\title{
Does the Time of Solitary Rapid Response Team Call Affect Patient Outcome?
}

\author{
Manoj Y Singh ${ }^{1}$, Ramprasad Vegunta ${ }^{2}$, Krishna Karpe ${ }^{3}$, Sumeet Rai ${ }^{4}$
}

\begin{abstract}
Objective: The study aimed to evaluate the effect of a single after-hours rapid response team (RRT) calls on patient outcome. Design: A retrospective cohort study of RRT-call data over a 3-year period.

Setting: A 600-bedded, tertiary referral, public university hospital.

Participants: All adult patients who had a single RRT-call during their hospital stay. Intervention: None.

Main outcomes measures: The primary outcome was to compare all-cause in-hospital mortality. The secondary outcomes were to study the hourly variation of RRT-calls and the mortality rate.

Results: Of the total 5,108 RRT-calls recorded, 1,916 patients had a single RRT-call. Eight hundred and sixty-one RRT-calls occurred during workhours (08:00-17:59 hours) and 1,055 during after-hours (18:00-7:59). The all-cause in-hospital mortality was higher (15.07\% vs 9.75\%, OR 1.64, $95 \% \mathrm{Cl} 1.24-2.17, p$ value 0.001$)$ in patients who had an after-hours RRT-call. This difference remained statistically significant after multivariate regression analysis (OR $1.50,95 \% \mathrm{Cl} 1.11-2.01, p$ value 0.001 ). We noted a lower frequency of hourly RRT-calls after-hours but were associated with higher hourly mortality rates. There was no difference in outcomes for patients who were admitted to ICU post-RRT-call.

Conclusion: Patients having an after-hour RRT-call appear to have a higher risk for hospital mortality. No causal mechanism could be identified other than a decrease in hourly RRT usage during after-hours.

Keywords: After-hour MET-call, After-hour RRT-call, Emergency medical team call, Hospital mortality, Medical emergency team call, Rapid response system call, Work-hour MET-call, Work-hour RRT-call.

Indian Journal of Critical Care Medicine (2020): 10.5005/jp-journals-10071-23322
\end{abstract}

\section{INTRODUCTION}

Resource allocation is unevenly distributed between the hospital work-hours and after-hours, and the implications of this imbalance have been studied in various settings. ${ }^{1-4}$ This uneven staffing can impact on patient care, delay in diagnostic and therapeutic interventions, ${ }^{5-7}$ and increase mortality. ${ }^{1,2,8-10}$ The effect of afterhours on the outcomes of single rapid response team (RRT)-call has never been exclusively studied before. After-hours could potentially impact RRT-call outcome in two ways. First, it can lead to an afferentlimb failure from missed or delayed RRT-calls. ${ }^{11,12}$ The reasons for this could be multifactorial, e.g., decreased staffing levels after-hours leading to decreased monitoring, poor skill-mix, and less education opportunities. Moreover, the effect of diminished level of senior input or supervision cannot be underestimated. Second, it can lead to an efferent limb failure due to limited skill-level and supervision of the RRT after-hours that could lead to delays in timely escalation of care and treatment. Studies have shown that almost a third of the in-hospital cardiac arrests that happened after-hours had delays in defibrillation and correspondingly survival was noted to be lower for patients having cardiac arrests at nights and/or weekends. ${ }^{13,14}$

Although the largest cluster-randomized control trial ${ }^{15}$ on rapid response system (RRS) failed to demonstrate a survival benefit by its implementation, a few recent studies ${ }^{16-18}$ and meta-analyses ${ }^{19,20}$ have reported an improved mortality. One of the many reasons why MERIT trial failed to decrease the hospital mortality was onethird of the RRT-calls were activated late. ${ }^{21}$ These delayed RRT-calls were more likely to occur during after-hours. Similar findings were reported in recent retrospective studies ${ }^{22,23}$ where the authors
${ }^{1-4}$ Department of Internal Medicine, Canberra Hospital, Canberra, Australia

Corresponding Author: Manoj Y Singh, Department of Internal Medicine, Canberra Hospital, Canberra, Australia, e-mail: Manoj. Singh@act.gov.au

How to cite this article: Singh MY, Vegunta R, Karpe K, Rai S. Does the Time of Solitary Rapid Response Team Call Affect Patient Outcome? Indian J Crit Care Med 2020;24(1):38-43.

Source of support: Nil

Conflict of interest: None

found that the group with delayed RRT-calls had a higher proportion of calls between midnight and 08:00 hours.

\section{Objective}

We undertook this project to test our hypothesis that the timing of the RRT-call had an effect on patient outcome. The primary aim was to compare the all-cause mortality of patients involved in a single RRT-call at hospital discharge, based on the time of their RRT-call. The secondary outcomes were to analyze the hourly pattern of medical emergency team (MET)-calls and their mortality rates, and to compare the ICU length of stay (LOS) and in-hospital mortality in the two study cohorts who were admitted to ICU after the RRT-call.

\section{Materials and Methods} Ethics Approval

The project was approved by ACT Health Human Research Ethics Committee (Ref. ETHLR 13.322).

(c) The Author(s). 2020 Open Access This article is distributed under the terms of the Creative Commons Attribution 4.0 International License (https://creativecommons. org/licenses/by-nc/4.0/), which permits unrestricted use, distribution, and non-commercial reproduction in any medium, provided you give appropriate credit to the original author(s) and the source, provide a link to the Creative Commons license, and indicate if changes were made. The Creative Commons Public Domain Dedication waiver (http://creativecommons.org/publicdomain/zero/1.0/) applies to the data made available in this article, unless otherwise stated. 


\section{Study Design}

Our study was a retrospective analysis of a prospectively collected data of all RRT-calls occurring at the Canberra Hospital (TCH). The following data was prospectively collected by the Rapid Response Committee (RRC) for each RRT-call: basic demographics, date, day, time and location of RRT, RRT trigger(s), outcome and location of patient at the end of RRT, and the eventual hospital stay and outcome. We identified all patients who had a single RRT-call during their hospitalization. We divided them into two cohorts depending on the time of RRT-call.

\section{Inclusion and Exclusion Criteria}

We identified all RRT-calls recorded from January 1, 2012 to December 31, 2014. We excluded patients who were $\leq 16$ years, RRT responses in patients admitted to Acute Mental Health Unit (AMHU), accidental RRT activations, outpatients, and those with incomplete data, from the study. All patients who have had recurrent RRT-calls were subsequently excluded from the final analysis. This was to avoid confounding from exposure to both a work-hour and an after-hour RRT call and the potential effect of recurrent RRT-calls on patient outcomes. All patients with documented preexisting not for resuscitation (NFR) were also excluded. These included the patient population where treatment limitations were established, at the time of RRT response, by the team attending the RRT-call.

\section{Study Hospital}

TCH is a 600-bedded, tertiary referral hospital in Australian Capital Territory (ACT). The ICU at the Canberra Hospital is a 31-bedded, level 3 medical-surgical ICU that treated over a 1,000 ventilated, high acuity patients per year during the study period. The unit is the only major referral and trauma center in the ACT and surrounding regional areas.

\section{Rapid Response Team}

A dedicated ICU outreach team responds to RRT-calls round the clock. During work-hours, this team consists of a dedicated intensivist, ICU outreach registrar, and an outreach nurse. During work-hours, the intensivist provides onsite supervision for every RRT-call. During after-hours, the team usually consists of an ICU outreach registrar under the supervision of an ICU senior registrar, who reports to an on-call ICU specialist. In the event of concurrent RRT calls, the team is lead by an ICU registrar or an emergency medicine (EM) registrar with similar hour-specific supervision levels.

\section{Definitions}

We defined work-hour RRT-call as one that occurred between 08:00 and 17:59 hours during weekdays (Monday-Friday). An after-hour RRT-call was defined as one that occurred between 18:00 and 07:59 hours on weekdays and any RRT call that occurred on a weekend regardless of the time. We used this definition on the basis of the normal working schedule in our ICU and the rostering pattern for medical and allied-health staff in the hospital. This also takes into account the difference in level of support from various clinical and nonclinical departments between work-hours and after-hours in the hospital. No attempt was made to account for public holidays that fell on weekdays during the study period.

\section{Statistical Analysis}

All continuous variables were expressed as median or mean with standard deviation (SD), as appropriate. All categorical variables expressed as numbers and percentages were compared using the $\chi^{2}$ test. Univariate and multivariate logistic regression analyses were undertaken using 11.0 version of STATA statistical software for each variable to assess predictors for mortality. All logistic regression results were reported as odds ratio (OR) with $95 \%$ confidence interval (Cl). A $p$ value of $<0.05$ was taken to indicate statistical significance.

\section{RESULTS}

A total of 5,108 RRT-calls were recorded during the study period of which $54 \%(2,397 / 4,438)$ were patients with a single RRT-call during their hospitalization. Among these, 481 patients with treatment limitations were excluded, leaving 1,916 patients for the final analysis (Flowchart 1).

Eight hundred and sixty-one patients had their RRT-calls during work-hours and 1,055 patients during after-hours. There was no statistically significant difference in baseline characteristics of the two study cohorts in terms of gender, median age, and age more than 75 but there were a higher proportion of medical stream patents in the work-hour cohort (Table 1). No data was available to compare the baseline disease severity of these two cohorts before they had their RRT-call. Table 1 also highlights the distribution of RRT-triggers in the study group.

\section{Primary Outcome}

The overall all-cause in-hospital mortality was $12.68 \%(243 / 1,916)$ for the study population. Mortality was higher in patients who had their RRT-call during after-hours compared to those during work-hours, $15.07 \%(159 / 1,055)$ vs $9.75 \%$ (84/861); OR 1.64 (95\% Cl 1.24-2.17), $p$ 0.001. Table 2 illustrates the distribution of RRT-triggers amongst those patients who died. Patients who had RRT-call after-hours for low glasgow coma scale (GCS) had significantly higher death rate compared to those during work-hours. Univariate and multivariate logistic regression analyses were undertaken for each variable to assess various predictors of mortality (Table 3 ). The significant predictors for all-cause mortality were as follows: age $\geq 75$ years, cardiac arrest at RRT-call, nonsurgical patient group, and an after-hour RRT-call.

Flowchart 1: Study consort chart

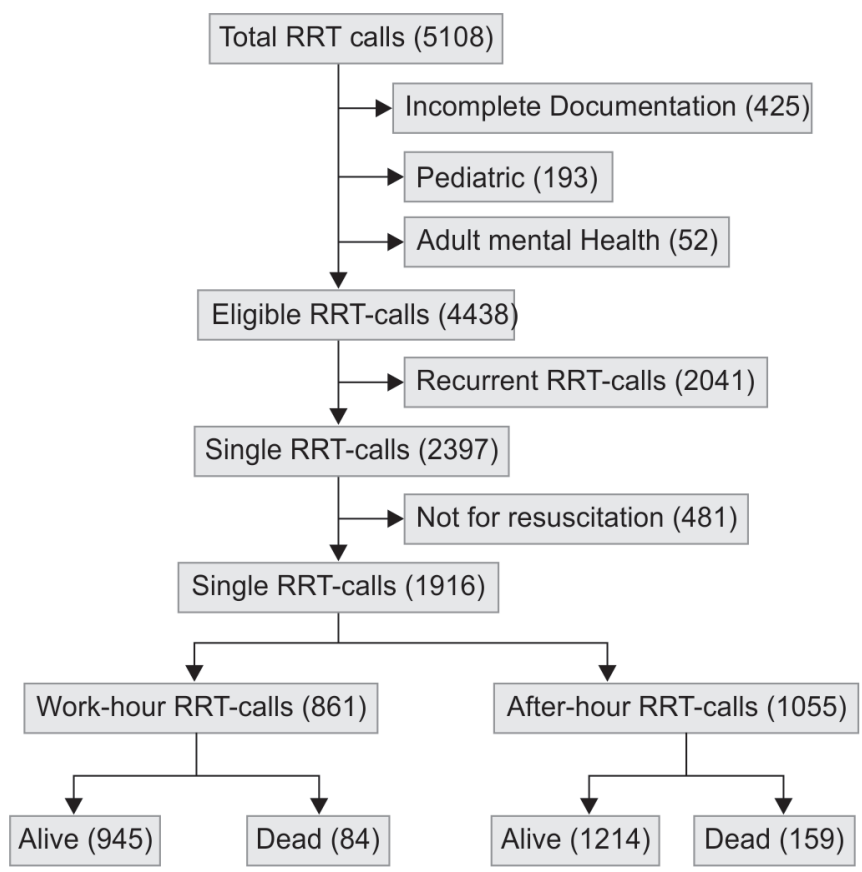


The after-hour cohort had a higher proportion of patients with cardiac arrest rates (6.2\% vs $4.3 \%$, respectively, $p$ value 0.07 ) but the mortality difference in the two groups was not statistically significant (61\% vs $51 \%$, respectively, $p$ value 0.14 ). We reanalyzed the mortality in the two study cohorts after excluding all patients with cardiac arrests (102 patients) to avoid any potential confounding and found that the statistical difference in mortality persisted between the two groups OR 1.60 ( $5 \% \mathrm{Cl} 1.12-2.14, p 0.001)$.

\section{Secondary Outcomes}

Figure $1 \mathrm{~A}$ shows the hourly distribution of all RRT-calls during the study period and the mortality rate as a percentage of the RRT-calls occurring each hour. On an hourly basis, more RRTs were triggered during work-hours (a total of $45 \%$ ). The mortality was highest (34.15\%) for RRT-calls that occurred between 05:00 and 05:59 hours. Figure 1B highlights the hourly odds ratio for death

Table 1: The baseline characteristics and RRT-call trigger pattern in the study population

\begin{tabular}{llll}
\hline & $\begin{array}{l}\text { Work-hour } \\
R R T \text {-call } \\
(n=861)(\%)\end{array}$ & $\begin{array}{l}\text { After-hour } \\
R R T \text {-call } \\
(n=1,055)(\%)\end{array}$ & p value \\
\hline Male & $463(54)$ & $570(54)$ & 0.91 \\
Female & $398(46)$ & $485(46)$ & 0.91 \\
Age (mean) & $62($ SD 18.67) & $61($ SD 19.51) & 0.46 \\
Patients aged $\geq 75$ & $243(28)$ & $288(27)$ & 0.85 \\
Medical & $551(64)$ & $620(59)$ & 0.02 \\
Surgical & $310(36)$ & $435(41)$ & 0.02 \\
RRT-call triggers & & & \\
Airway concerns & $15(1.7)$ & $20(1.9)$ & 0.80 \\
Hypotension (systolic & $219(25.4)$ & $234(22.2)$ & 0.09 \\
blood pressure & & & \\
<90 mm Hg) & & & \\
Cardiac arrest & $37(4.3)$ & $65(6.2)$ & 0.07 \\
Decreased GCS & $200(23.2)$ & $230(21.8)$ & 0.45 \\
Bradycardia & $15(1.7)$ & $19(1.8)$ & 0.9 \\
Tachycardia & $64(7.4)$ & $130(12.3)$ & 0.05 \\
Respiratory arrest & 4 & 2 & 0.2 \\
Prolonged seizure & $36(3)$ & $31(3)$ & 0.14 \\
Tachypnea & $70(6.6)$ & $113(10.7)$ & 0.05 \\
Bradypnea & 5 & 5 & 0.7 \\
Worried & $195(18.5)$ & $204(19.3)$ & 0.07 \\
Unspecified & 1 & 2 & 0.68 \\
\hline
\end{tabular}

for all RRT-calls by comparing them with those occurring between 11:00 and 11:59 hours as the control.

A total of 767 (40\%) patients were admitted to ICU following a single RRT-call, 54.6\% (419/767) after an after-hour RRT-call and 45.4\% (348/767) after RRT-call during work-hours. Table 4 highlights the baseline characteristics of patients admitted to ICU after their RRT-call.

There was no statistically significant difference in the in-hospital mortality rate of patients who were admitted to ICU in the two groups [ $20 \%$ vs $18 \%$, OR 1.25 ( $95 \% \mathrm{Cl} 0.86-1.81)$, $p$ value 0.23 ]. The mean ICU LOS was similar in the two groups (Table 4).

\section{Discussion}

Our study findings showed that single RRT-calls are common in hospitals and the time of single after-hours RRT-call could impact patient outcome. In addition, it also highlights the worse outcomes for patients whose RRT-call was triggered for decreased GCS-score.

The results of our study confirm a few observations made by previous authors. First, the hourly RRT-call pattern is nonuniform over the 24 -hour cycle. In our study, $45 \%$ of the total RRT-calls were triggered during the 10-hour work-hour period. In their epidemiological study of RRS amongst 11 hospitals in New Zealand over 2 weeks period between October and December 2014, Psirides reviewed 351 RRS-calls occurring in 313 patients. They found that $43.4 \%$ of RRS-call occurred during the work-hours (08:00-17:00). ${ }^{24}$ Flabouris et al. relooked at the timing of RRT activations for the patients in MERIT study. ${ }^{25}$ They reported most (31\%) RRT-calls were triggered during 06:01-12:00 hours and least (18\%) between 18:01 and 24:00 hours period. However, in a multicenter study involving five Australian, and one Canadian and Swedish hospital, the authors did not find significant difference in proportion of RRT-calls triggered between the two time periods. ${ }^{26}$ In a largest retrospective study of 282,710 RRT calls from 274 hospitals across US over 10-year period (2005-2015), Churpek et al. reported lowest frequency of RRT-calls between 01:00 and 6:59 hours. ${ }^{27}$ Recently, Fernando et al. reviewed over 6,023 RRT activations from two Canadian hospitals within a single tertiary care system over 4-year period (May 2012 to May 2016). They reported though 55.9\% of RRT-call during after-hours (17:00-07:59 hours), there was a trend toward lower RRT activations during after-hours per 1,000 hospital admissions. ${ }^{28}$

Second, after-hours RRT-calls are associated with worst outcomes. In 2010, Calzavacca et al. compared the outcomes of multiple and single RRT-calls occurring at a tertiary metropolitan

Table 2: RRT-call trigger pattern based on mortality outcomes

\begin{tabular}{|c|c|c|c|c|c|}
\hline \multirow[b]{2}{*}{ Criterion for MET activation } & \multicolumn{2}{|c|}{ Work-hour RRT-call } & \multicolumn{2}{|c|}{ After-hour RRT-call } & \multirow[b]{2}{*}{$p$ value } \\
\hline & Alive & $\begin{array}{l}\text { Dead }(n=84) \\
\text { (mortality\%) }\end{array}$ & Alive & $\begin{array}{l}\text { Dead }(n=159) \\
\text { (mortality\%) }\end{array}$ & \\
\hline Airway & 15 & 0 & 18 & 2 & 0.36 \\
\hline Hypotension & 200 & $19(8.6)$ & 209 & $25(10.6)$ & 0.47 \\
\hline Cardiac arrest & 18 & $19(51.35)$ & 22 & $43(66.15)$ & 0.14 \\
\hline Decreased GCS & 181 & $13(6.5)$ & 200 & $30(13)$ & 0.02 \\
\hline Tachycardia & 59 & $5(7.8)$ & 121 & $9(6.9)$ & 0.82 \\
\hline Tachypnea & 55 & $15(21.42)$ & 88 & $25(22.12)$ & 0.91 \\
\hline Worried & 183 & $12(6.15)$ & 181 & $23(11.27)$ & 0.07 \\
\hline Bradypnea & 5 & 0 & 4 & 1 & 0.45 \\
\hline Prolonged seizure & 35 & 1 & 30 & 1 & 0.91 \\
\hline
\end{tabular}


Melbourne hospital reported that office-hours RRT-calls were associated with lower mortality (OR $0.7095 \% \mathrm{Cl} 0.50-0.97, p$ value 0.035 ) in their subgroup analysis. ${ }^{29}$ Churpek et al. reported highest mortality among patients who had MET-calls in the 07:00th hour and was statistically significant when compared to those occurring at noon (18.8\% vs $13.8 \%$, adjusted OR $1.41,95 \% \mathrm{Cl} 1.31-1.52, p$ value $<0.001) .{ }^{27}$ Not to our surprise, the mortality rate of patients who had single RRT-call also varied hourly. In our study, the mortality was highest for RRT-calls occurring during 04:00-04:59 (24.39\%) and 05:00-05:59 hours (34.15\%). Fernando et al. found that after-hours RRT-calls had higher mortality (OR 1.34, 95\% Cl 1.26-1.40, $p$ value $<$ 0.02), especially if the RRT were triggered between 23:00 and 24:00 hours (OR 1.34, 95\% Cl 1.01-1.56) and 06:00-07:00 hours (OR 1.30, $95 \% \mathrm{Cl} 1.09-1.61) .{ }^{28}$ In their study, the after-hours RRT-calls were

Table 3: Multivariate regression analysis

\begin{tabular}{lll}
\hline & Adjusted OR $(95 \% \mathrm{Cl})$ & $p$ \\
\hline Age $\geq 75$ years & $1.86(1.39-2.49)$ & 0.001 \\
After-hour RRT-call & $1.50(1.11-2.01)$ & 0.001 \\
Cardiacarrest & $5.34(3.82-7.45)$ & 0.001 \\
Nonsurgical & $1.97(1.46-2.65)$ & 0.001 \\
admission & & \\
\hline
\end{tabular}

associated with significantly longer latency from symptom onset. Also, there was a difference in the primary team who activated RRT-calls in their study (hematology and orthopedics more during work-hours and neurosurgery and medical oncology more during after-hours).

Third, the phenomena of increased frequency of cardiac arrests occurring after-hours are well-known and the mortality is higher among these patients. ${ }^{13,14,30-32}$ Jones et al. found that the cardiac arrest rates peaked during periods of low RRT activity between 24:00 and 08:00 hours. ${ }^{31}$ Similar to our study, they also reported higher mortality for patients having cardiac arrest between 04:00 and 05:59 hours.

Fourth, a significant proportion of patients get admitted to ICU post-RRT-call. The incidence and timing of this depends on the characteristics of the study population and the hospital in which the study was conducted. Jaderling et al. found that nearly $57 \%$ of patients got admitted to ICU after-hours (17:00-08:00 hours) after a RRT-call. ${ }^{33}$ On the contrary, Fernando et al. reported workhours RRT calls ( 30.5 vs $27.8 \%$, $p$ value 0.02 ) were significantly more associated with ICU admissions in their cohort. ${ }^{28}$ In MERIT study, the incidence of ICU admissions was $20.7 \%$ (106/512) in control hospitals compared to $17.11 \%(319 / 1,864)$ in the MET hospitals. ${ }^{25}$ Recently, Le Guen et al. reported an incidence of $17 \%$ in their study on ICU
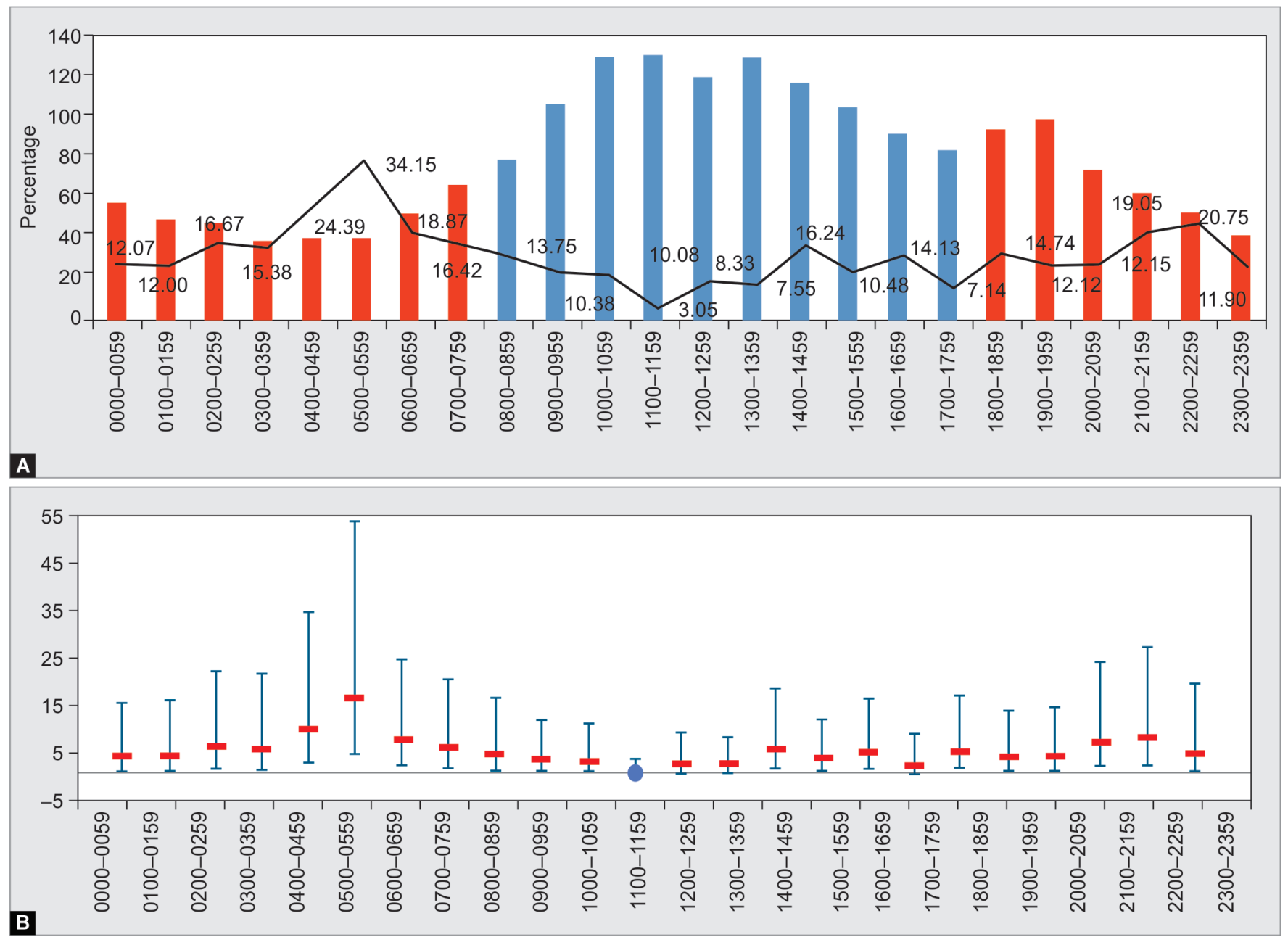

Figs $1 \mathrm{~A}$ and B: Hourly distribution of RRT-calls occurring each hour of the day and associated mortality rate and odds ratio: (A) Blue shaded columns: work-hours; red shaded columns: after-hours; black line: mortality rate each hour; (B) Hourly odds ratio with $95 \% \mathrm{Cl}$ when compared to deaths at 11:00-11:59 (blue dot) 
Table 4: Baseline characteristics and outcomes of patients admitted to ICU post-RRT-call in the study groups

\begin{tabular}{llll}
\hline & $\begin{array}{l}\text { Work-hour RRT- } \\
\text { call }(n=348)(\%)\end{array}$ & $\begin{array}{l}\text { After-hour RRT-call } \\
(n=419)(\%)\end{array}$ & $p$ value \\
\hline Male & $215(62)$ & $256(61)$ & 0.5 \\
Female & $133(38)$ & $163(39)$ & 0.5 \\
Age (Mean) & $65($ SD 16.02) & $63($ SD 17.01) & 0.4 \\
Patients aged $\geq 75$ & $85(29)$ & $113(24)$ & 0.14 \\
APACHEII (mean) & $17.3($ SD 7.2) & $17.05($ SD 7.1) & - \\
APACHE III (mean) & $63.30($ SD 28.3) & $63.20($ SD 27.95) & - \\
Mortality & $58(16.7)$ & $84(20)$ & 0.23 \\
$\begin{array}{l}\text { Mean length } \\
\text { of stay }\end{array}$ & 84 hours & $91.43($ SD 5.93) & 0.20 \\
\hline
\end{tabular}

admission rates post RRS activation in a Melbourne metropolitan hospital. ${ }^{34}$ While in a study from Mayo Clinic in US, the ICU admission rate was much higher (64.92\%) after their first RRT-call. ${ }^{22}$ Compared to the Australian data, ${ }^{25,34}$ our study had a higher ICU transfer rate post-RRT-calls, at $40 \%$. One of the reasons to explain this difference could be that many patients may get admitted to ICU post-RRS referrals rather than post-RRT-call, as reported by Downar et al. ${ }^{35}$

Fifth, the overall hospital mortality of patients having RRTcalls is high. Though in our study, it was lower than the Australian average published earlier ( $12.68 \%$ vs $25 \%$, respectively). ${ }^{36}$ In their retrospective of 2,237 RRT reviews in a tertiary hospital in Melbourne, Calzavacca et al. ${ }^{29}$ reported an overall mortality of $16.6 \%(145 / 873)$ in patients with single RRT reviews with no NFR status. While Stelfox et al. ${ }^{37}$ reported hospital mortality rate of $21.92 \%$ for patients with single RRT-call who were not admitted to ICU in Canadian hospitals, Fernando et al. reported nearly $30.8 \%$ in their cohort. ${ }^{28}$ It would be difficult to ascertain the reasons to explain this difference, but as discussed earlier, higher proportions of ICU admission rates post-RRT-call in our study might have influenced their hospital outcome.

Finally, it is important to focus on the cohort with single RRT-call as they represent a significant proportion of patients who have RRS activation. Two Australian studies reported an incidence of $72.9 \%$ (among 1,480 responses over a year) ${ }^{38}$ and 77.5\% (among 2,237 RRT-calls over 2 -year period) ${ }^{29}$ for single RRT-call in their hospital cohort. In multicenter retrospective study, Stelfox et al. compared the outcomes of patients with recurrent RRT-calls to single RRT calls who were admitted to two community and two tertiary Canadian hospitals. Among the 3,200 RRT-calls they analyzed over 2-year period, $89.5 \%$ of these were solitary. ${ }^{37}$ One of the reasons for a lower proportion of single RRT-call in our study could be due to the rigorous exclusion criteria we used in our study.

The underlying reasons to explain the difference in outcomes between the cohort groups cannot be fully elucidated, due to multiple limitations inherent to a retrospective study design. In a prospective study of factors influencing the outcome of patients after an RRT review, the authors found NFR status, delayed RRT-calls, and medical admissions to be associated with worse outcomes. ${ }^{39}$ The disproportionately larger number of nonsurgical patients in the work-hour cohort makes our result even more significant in light of the above-mentioned finding. The influence of delayed calls is well-reported and one could argue that given that delayed RRT-calls are more common after-hours, this could have possibly influenced the outcome in our study.
Another possible factor that could explain this discrepancy could be that the after-hour cohort might be sicker. Whilst there is no baseline data to substantiate this accurately, the RRT-call trigger pattern (Table 1) indicates that there were more patients with tachypnea and tachycardia in the after-hour group. Churpeck et al. also reported that patients with RRT calls after-hours had more deranged vital signs and more likely to have respiratory trigger for RRT when compared to those at noon. ${ }^{27}$ Interestingly in our study, more deaths occurred amongst the after-hour patient group in who RRT was triggered because of low GCS (Table 4).

From the results of this study, we propose a multicenter prospective study to assess the effect of time of RRT-call on patient outcome. The study should also assess the baseline severity of patients admitted to hospital and its influence on patient outcome.

\section{Strengths and Limitations}

Our study is one of the few which looked into the impact of timing of a single RRT-call on patient outcome during their hospitalization. In doing so, we tested the hypothesis that timing of RRT-calls affected patient outcomes. We excluded some of the confounders like the impact of multiple RRT-calls and treatment limitations on patient outcome. It could potentially have the limitations inherent to a retrospective design and cannot account for multiple unknown confounding factors. Moreover, its single-center study design limits its external validity. Analysis of the association of afterhours RRT-call with mortality is complex, and insufficient data to risk-adjust all patients by their baseline severity of illness. Other limitations include lack of information regards to time and date of procedures, relevant staffing and skill mix data and the albeit minor but potential confounder from the lack of public holiday data in the study. Addressing these issues should be a key consideration for future research.

\section{Conclusion}

In this study, significant proportions of patients had single RRTcall during hospitalization. There was decreased RRT-call usage overnight and patients with single after-hour RRT-call appear to have an increased all cause in-hospital mortality.

\section{References}

1. Becker DJ. Do hospitals provide lower quality care on weekends? Health Serv Res 2007;42(4):1589-1612. DOI: 10.1111/j.14756773.2006.00663.x

2. Needleman J, Buerhaus P, Pankratz VS, Leibson CL, Stevens SR, Harris M. Nurse staffing and inpatient hospital mortality. N Engl J Med 2011;364(11):1037-1045. DOI: 10.1056/NEJMsa1001025.

3. Tong PK. The effects of California minimum nurse staffing laws on nurse labor and patient mortality in skilled nursing facilities. Health Econ 2011;20(7):802-816. DOI: 10.1002/hec.1638.

4. Mitra B, Cameron PA, Fitzgerald MC, Bernard S, Moloney J, Varma D, et al. "After-hours" staffing of trauma centres and outcomes among patients presenting with acute traumatic coagulopathy. Med J Aust 2014;201(10):588-591. DOI: 10.5694/mja13.00235.

5. Wood SD, Coster S, Norman I. Comparing the monitoring of patients transferred from a critical care unit to hospital wards at after-hours with day transfers: an exploratory, prospective cohort study. J Adv Nurs 2014;70(12):2757-2766. DOI: 10.1111/jan.12410.

6. Schwartz DA, Medina M, Cotton BA, Rahbar E, Wade CE, Cohen AM, et al. Are we delivering two standards of care for pelvic trauma? Availability of angioembolization after hours and on weekends 
increases time to therapeutic intervention. J Trauma Acute Care Surg 2014;76(1):134-139. DOI: 10.1097/TA.0b013e3182ab0cfc.

7. Ting JY, Humphrey KJ. After hours medical ward duties in a teaching hospital. Aust Health Rev 2005;29(1):37-42. DOI: 10.1071/AH050037.

8. Ansa V, Otu A, Oku A, Njideoffor U, Nworah C, Odigwe C. Patient outcomes following after-hours and weekend admissions for cardiovascular disease in a tertiary hospital in Calabar, Nigeria. Cardiovasc J Afr 2016;27(5):328-332. DOI: 10.5830/CVJA-2016-025.

9. Lee KG, Indralingam V. A study of weekend and off-hour effect on mortality in a public hospital in Malaysia. Med J Malaysia 2012;67(5):478-482.

10. Singh MY, Nayyar V, Clark PT, Kim C. Does after-hours discharge of ICU patients influence outcome? Crit Care Resusc 2010;12(3):156-161.

11. Trinkle RM, Flabouris A. Documenting rapid response system afferent limb failure and associated patient outcomes. Resuscitation 2011;82(7):810-814. DOI: 10.1016/j.resuscitation.2011.03.019.

12. Sandroni C, Cavallaro F. Failure of the afferent limb: a persistent problem in rapid response systems. Resuscitation 2011;82(7):797-798. DOI: 10.1016/j.resuscitation.2011.04.012.

13. Peberdy MA, Ornato JP, Larkin GL, Braithwaite RS, Kashner TM, Carey SM, et al. Survival from in-hospital cardiac arrest during nights and weekends. JAMA 2008;299(7):785-792. DOI: 10.1001/jama.299.7.785.

14. Chan PS, Krumholz HM, Nichol G, Nallamothu BK, American Heart Association National Registry of Cardiopulmonary Resuscitation Investigators. Delayed time to defibrillation after in-hospital cardiac arrest. N Engl J Med 2008;358(1):9-17. DOI: 10.1056/NEJMoa0706467.

15. Hillman K, Chen J, Cretikos M, Bellomo R, Brown D, Doig G, et al. Introduction of the medical emergency team (MET) system: a clusterrandomised controlled trial. Lancet 2005;365(9477):2091-2097. DOI: 10.1016/S0140-6736(05)66733-5.

16. Salvatierra G, Bindler RC, Corbett C, Roll J, Daratha KB. Rapid response team implementation and in-hospital mortality. Crit Care Med 2014;42(9):2001-2006. DOI: 10.1097/CCM.0000000000000347.

17. Ludikhuize J, Brunsveld-Reinders AH, Dijkgraaf MG, Smorenburg SM, de Rooij SE, Adams R, et al. Outcomes associated with the nationwide introduction of rapid response systems in The Netherlands. Crit Care Med 2015;43(12):2544-2551. DOI: 10.1097/CCM.0000000000001272.

18. Brunsveld-Reinders AH, Ludikhuize J, Dijkgraaf MG, Arbous MS, de Jonge $\mathrm{E}, \mathrm{COMET}$ study group. Unexpected versus all-cause mortality as the endpoint for investigating the effects of a rapid response system in hospitalized patients. Crit Care 2016;20(1):168. DOI: 10.1186/ s13054-016-1339-9.

19. Maharaj R, Raffaele I, Wendon J. Rapid response systems: a systematic review and meta-analysis. Crit Care 2015;19:254. DOI: 10.1186/s13054015-0973-y.

20. Solomon RS, Corwin GS, Barclay DC, Quddusi SF, Dannenberg MD. Effectiveness of rapid response teams on rates of in-hospital cardiopulmonary arrest and mortality: a systematic review and metaanalysis. J Hosp Med 2016;11(6):438-445. DOI: 10.1002/jhm.2554.

21. Chen J, Bellomo R, Flabouris A, Hillman K, Assareh H, Ou L. Delayed emergency team calls and associated hospital mortality: a multicenter study. Crit Care Med 2015;43(10):2059-2065. DOI: 10.1097/ CCM.0000000000001192.

22. Barwise A, Thongprayoon C, Gajic O, Jensen J, Herasevich V, Pickering BW. Delayed rapid response team activation is associated with increased hospital mortality, morbidity, and length of stay in a tertiary care institution. Crit Care Med 2016;44(1):54-63. DOI: 10.1097/ CCM.0000000000001346.

23. Sundararajan K, Flabouris A, Thompson C. Diurnal variation in the performance of rapid response systems: the role of critical care services-a review article. J Intensive Care 2016;4:15. DOI: 10.1186/ s40560-016-0136-5.
24. Psirides AJ, Hill J, Jones D. Rapid response team activation in New Zealand hospitals-a multicentre prospective observational study. Anaesth Intensive Care 2016;44(3):391-397. DOI: 10.1177/0310057X1604400314.

25. Flabouris A, Chen J, Hillman K, Bellomo R, Finfer S, MERIT Study Investigators from the Simpson Centre, et al. Timing and interventions of emergency teams during the MERIT study. Resuscitation 2010;81(1):25-30. DOI: 10.1016/j.resuscitation.2009.09.025.

26. Medical Emergency Team End-of-Life Care investigators. The timing of rapid-response team activations: a multicentre international study. Crit Care Resusc 2013;15(1):15-20.

27. Churpek MM, Edelson DP, Lee JY, Carey K, Snyder A, American Heart Association's Get With The Guidelines-Resuscitation Investigators. Association between survival and time of day for rapid response team calls in a national registry. Crit Care Med 2017;45(10):1677-1682. DOI: 10.1097/CCM.0000000000002620.

28. Fernando SM, Reardon PM, Bagshaw SM, Scales DC, Murphy K, Shen J, et al. Impact of nighttime rapid response team activation on outcomes of hospitalized patients with acute deterioration. Crit Care 2018;22(1):67. DOI: 10.1186/s13054-018-2005-1.

29. Calzavacca P, Licari E, Tee A, Mercer I, Haase M, Haase-Fielitz A, et al. Features and outcome of patients receiving multiple medical emergency team reviews. Resuscitation 2010;81(11):1509-1515. DOI: 10.1016/j.resuscitation.2010.06.017.

30. Jones-Crawford JL, Parish DC, Smith BE, Dane FC. Resuscitation in the hospital: circadian variation of cardiopulmonary arrest. Am J Med 2007;120(2):158-164. DOI: 10.1016/j.amjmed.2006.06.032.

31. Jones D, Bellomo R, Bates S, Warrillow S, Goldsmith D, Hart G, et al. Patient monitoring and the timing of cardiac arrests and medical emergency team calls in a teaching hospital. Intensive Care Med 2006;32(9):1352-1356. DOI: 10.1007/s00134-006-0263-x.

32. Herlitz J, Bang A, Alsen B, Aune S. Characteristics and outcome among patients suffering from in hospital cardiac arrest in relation to whether the arrest took place during office hours. Resuscitation 2002;53(2):127-133. DOI: 10.1016/S0300-9572(02)00014-X.

33. Jaderling G, Bell M, Martling CR, Ekbom A, Bottai M, Konrad D. ICU admittance by a rapid response team versus conventional admittance, characteristics, and outcome. Crit Care Med 2013;41(3):725-731. DOI: 10.1097/CCM.0b013e3182711b94.

34. Le Guen MP, Tobin AE, Reid D. Intensive care unit admission in patients following rapid response team activation: call factors, patient characteristics and hospital outcomes. Anaesth Intensive Care 2015;43(2):211-215. DOI: 10.1177/0310057X1504300211.

35. Downar J, Barua R, Rodin D, Lejnieks B, Gudimella R, McCredie V, et al. Changes in end of life care 5 years after the introduction of a rapid response team: a multicentre retrospective study. Resuscitation 2013;84(10):1339-1344. DOI: 10.1016/j.resuscitation.2013. 03.003.

36. ANZICS-CORE MET dose investigators. Mortality of rapid response team patients in Australia: a multicentre study. Crit Care Resusc 2013;15(4):273-278.

37. Stelfox HT, Bagshaw SM, Gao S. Characteristics and outcomes for hospitalized patients with recurrent clinical deterioration and repeat medical emergency team activation. Crit Care Med 2014;42(7):16011609. DOI: $10.1097 / C C M .0000000000000315$.

38. Considine J, Charlesworth D, Currey J. Characteristics and outcomes of patients requiring rapid response system activation within hours of emergency admission. Crit Care Resusc 2014;16(3):184-189.

39. Calzavacca P, Licari E, Tee A, Egi M, Haase M, Haase-Fielitz A, et al. A prospective study of factors influencing the outcome of patients after a medical emergency team review. Intensive Care Med 2008;34(11):2112-2116. DOI: 10.1007/s00134-008-1229-y. 